\title{
An overview of thundersnow
}

\section{David M. Schultz ${ }^{1}$ and R. James Vavrek ${ }^{2}$}

${ }^{1}$ University of Helsinki and Finnish Meteorological Institute, Helsinki, Finland

${ }^{2}$ Henry W. Eggers School, Hammond, Indiana, USA

Lightning and thunder are commonly observed during the warm season from cumulonimbus clouds. These thunderstorms may be accompanied by heavy rain, hail, strong winds, and possibly tornadoes. During winter, however, snowstorms with heavy snowfall can occasionally produce lightning and thunder. The combination of snow and lightning/thunder is called 'thundersnow' (Figure 1).
For example, two notable thundersnow events have struck the United Kingdom. On 28 January 2004, a strong cold front and squall line passed through much of southern Britain, producing thundersnow, hail, gusty winds, and a tornado at Coombe Down, Bath. The wet snow froze, causing numerous traffic problems during the evening rush hour. In another example, during one six-hour period of convection on 3/4 January 2008 in Belfast, Northern Ireland, 12-15 centimetres of snow fell. One lightning strike disabled a substation in Lisburn, causing 13500 homes to be without electricity, according to the TORRO database.

The United States is not immune to thundersnow either. An early-season snowstorm, named 'Aphid', struck Buffalo, New York, on 12 October 2006 yielding cloudto-ground (CG) lightning strokes at rates of
$10+$ strikes per minute during the height of the storm. Another event occurred a few months later on 1 December 2006 in Columbia, Missouri, when more than 38 centimetres of wet snow fell overnight, with a period of lightning and thunder between midnight and 1 a.m. The metro area was paralyzed the next morning by the heavy snowfall.

In the USA, only $1.3 \%$ of cool-season (October-May) thunderstorms report incidences with snowfall, and only $0.07 \%$ of reported snowfalls are associated with lightning or thunder (Curran and Pearson, 1971). Thus, thundersnow is an exceptionally uncommon event. In addition, thundersnow storms generally produce fewer lightning strokes than thunderstorms with rain during the warm season. For example, in one thundersnow event in Utah during 2002,

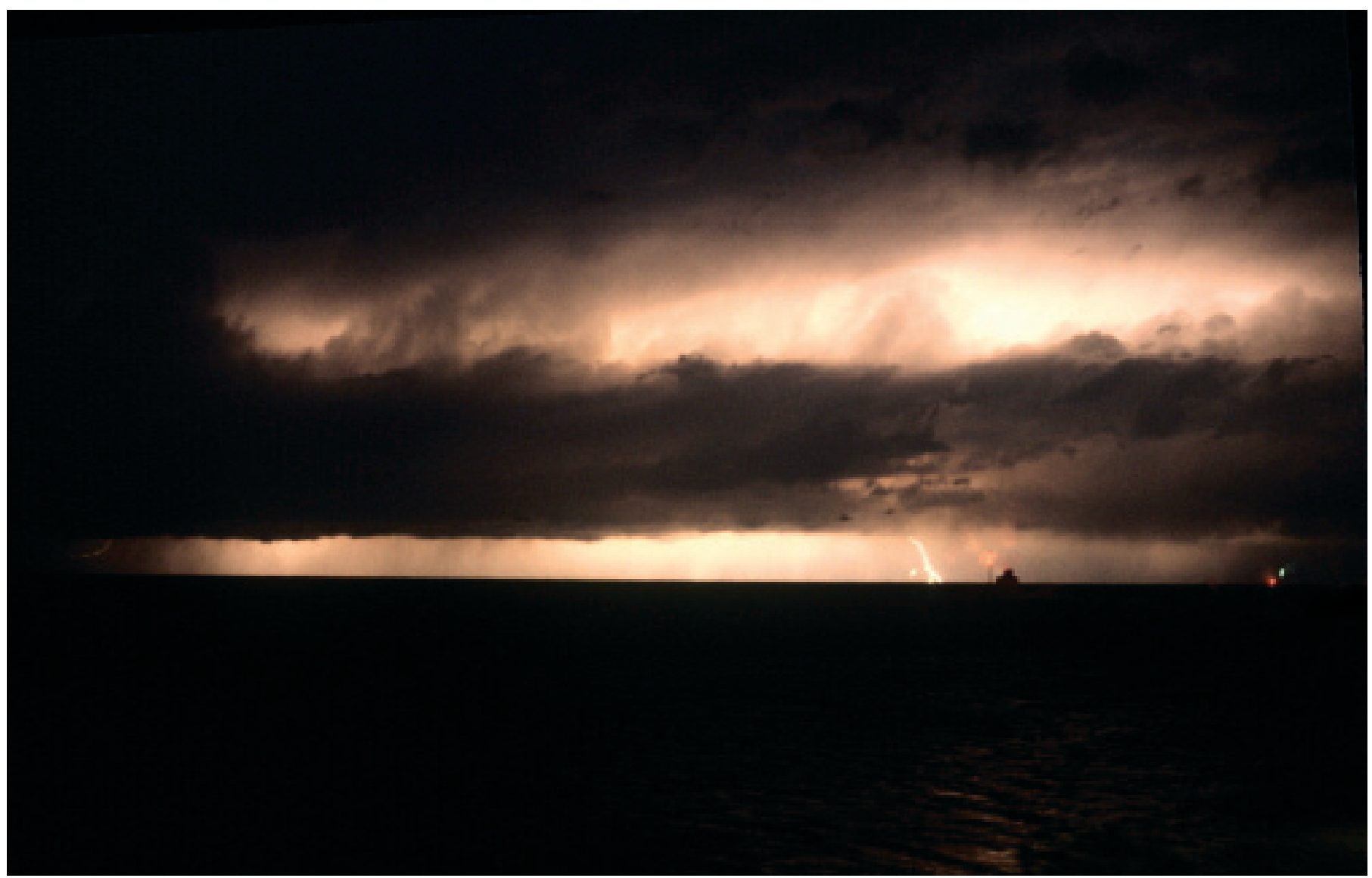


the National Lightning Detection Network recorded more than 50 CG lightning strokes in one hour. In contrast, warm-season thunderstorms can produce hundreds to thousands of strokes per hour.

Observations of lightning and thunder with snowstorms have been documented since the nineteenth century in the Western Hemisphere (Herschel, 1888) and in China since 1099 (Wang and Chu, 1982). Chinese warriors believed thundersnow storms were precursors to enemy attacks (Wang and Chu, 1982). Despite this long history of observations, little is known about thundersnow, partly due to the rarity of such storms compared to non-thundering snowstorms and partly due to the lack of direct observations inside the clouds producing lightning. Furthermore, light from lightning and sound from thunder are more likely to be absorbed by snow than in a comparable situation during heavy rain (Fraser and Bohren, 1992), making observations of thundersnow more difficult. A greater appreciation of the threats of thundersnow, new observing instruments, and a focused research and forecasting programme are helping to improve our understanding of thundersnow events. The result is that science is only starting to reveal the mysteries inside such storms.

The purpose of this article is to summarize our current understanding about this unusual wintertime event. This article describes where and when thundersnow happens, the ingredients needed to make thundersnow, and new efforts at understanding and forecasting the occurrence of thundersnow.

\section{Occurrence}

We know little about the global distribution of thundersnow events because they tend to occur over small areas. Even at their most widespread, thundersnow events may cover only a few hundred square kilometres. Thundersnow has been observed in many northern countries in the Northern Hemisphere, including the USA, Canada, Finland, the British Isles, western Norway, northern Europe, as well as over the Sea of Japan and the North Sea. Climbers scaling Mt Everest and other high peaks have reported thundersnow during their ascent, causing some anxious moments. Thundersnow can also lead to the closure and evacuation of ski areas for the protection of skiers and personnel.

Most research on thundersnow climatologies and environments has been carried out over the USA, which will be the focus of this article. Over the USA, there are two favoured regions for thundersnow (Figure 2 ). The largest area extends from the central USA northeastward across the Midwest and Great Lakes region to New England. The other region is the Intermountain West. Why these

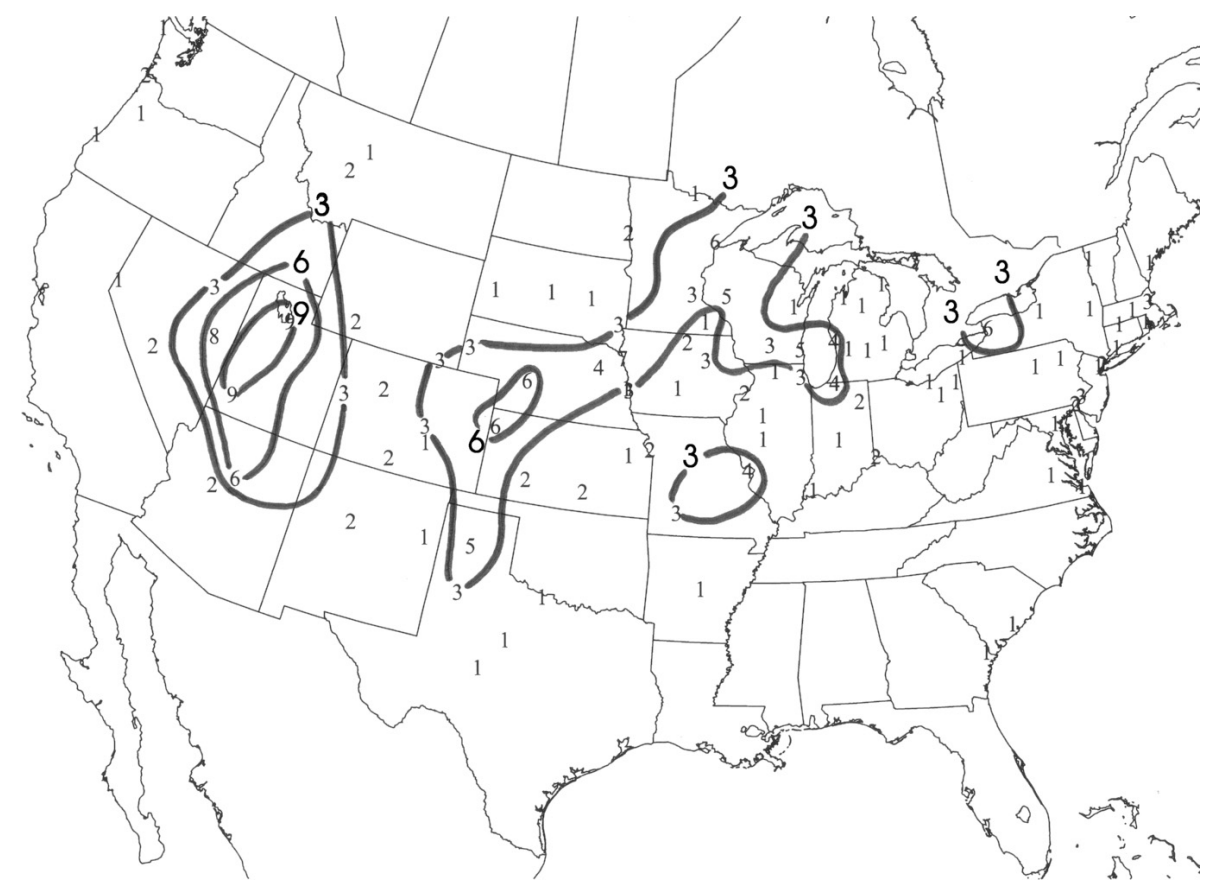

Figure 2. Number of thundersnow occurrences during 1961-1990 (Market et al., 2002).

regions are favoured for thundersnow will be addressed later in this article.

\section{A recipe for thundersnow}

Thundersnow storms are convective storms, generally producing prodigious snowfall accumulations (Crowe et al., 2006). Research scientists and forecasters have found that thinking of convective storms in terms of a recipe is useful. The recipe to make a convective storm has three ingredients (Johns and Doswell, 1992).

1. Moisture - abundant water vapour in the air to form clouds and precipitation. The moisture can be transported long distances before falling as precipitation or can originate locally. Long-distance transport might occur in cases of thundersnow over the central USA where moisture may originate from the Gulf of Mexico. In contrast, moisture might come from local sources, as when moisture is evaporated into cold air blowing across a relatively warm body of water, such as a large lake, bay, or ocean, as in the case of lakeeffect thundersnow events.

2. Lift - a mechanism to raise moist air to form clouds and precipitation. Sources of lift to produce a convective storm include the rising of warm air over a front or air rising up the side of a hill or mountain.

3. Unstable temperature profile - rapidly decreasing temperature with height, which can favour vigorous upward motion in the atmosphere. The layer in which clouds are unstable should have temperatures decreasing with height at a rate of more than 6 degCkm ${ }^{-1}$ for most convective storms to form (Schultz, 1999; Market et al., 2006). Such an unstable temperature profile favours strong, upward motion to lift moist air, ensuring an adequate supply of moisture into the clouds and allowing the process of electrification to occur. The origin of these unstable profiles is typically warm conditions in the lowest few kilometres above the Earth's surface and cold air at levels of three to eight kilometres, generally associated with disturbances in the jet stream.

A fourth ingredient needed specifically for thundersnow is cold air.

4. Cold air - below-freezing temperatures within clouds and near the ground. Without cold air in these layers, precipitation would reach the surface as rain.

Although most convective storms produce lightning, not all do. Next, we examine the conditions required for the electrification of clouds.

\section{Lightning}

Although the exact mechanism for lightning production within a cloud is not fully understood, scientists believe the formation of electrical charges that are precursors to lightning involves the interaction between different types of ice in clouds.

In what is called the mixed-phase region in clouds - the region in clouds at temperatures between $-10^{\circ} \mathrm{C}$ and $-40^{\circ} \mathrm{C}$ - supercooled liquid water and ice can co-exist. 
These supercooled liquid-water droplets freeze on ice particles (a process called 'riming') and produce a granulated ice particle called 'graupel'. Strong upward vertical motion, associated with lifting parcels through the unstable temperature profile, is necessary for supplying moisture to the cloud to allow abundant supercooled liquid water to create graupel. Laboratory and field studies have found that collisions between graupel and other non-rimed ice particles are the primary mechanism for the production of electrical charges. As larger rimed particles fall through clouds and smaller non-rimed particles ascend in upward vertical motions within clouds, these charges become separated.

The separation of these charges eventually may produce an electric field that becomes so large that dielectric breakdown happens, producing an electrical spark - the lightning stroke. The path of lightning is called a 'channel' and is an electrically conductive, ionized tube. Most channels form between points within the cloud, producing 'intra-cloud' lightning. By comparison, fewer channels may form between cloud and Earth, forming CG lightning. Clearly, CG lightning poses a greater threat to people than intra-cloud lightning.

Many questions remain about how charging occurs within warm-season thunderstorms, so scientists do not know whether charging differs in electrified winter storms, where far fewer observations exist. One significant difference between warm- and cold-season storms is the altitude of the charged regions in clouds. Because the atmosphere is warmer during the summer and the mixed-phase region is where charging occurs, the charged areas of the cloud tend to be higher during warm-season storms: three to ten kilometres above the ground, compared to one to three kilometres for winter thunderstorms.

The majority of CG strokes during warmseason thunderstorms transport negative charge from the cloud to the ground. Many CG lightning strokes during thundersnow events, however, lower positive charge from the cloud to the ground. Scientists have several hypotheses about why such differences occur, but firm answers to these questions are elusive.

Now that we have the ingredients needed to produce thundersnow and the mechanisms by which electrification occurs, we can better explain the geographic locations in the USA where thundersnow occurs.

\section{Weather patterns}

The four ingredients referred to above help explain why thundersnow events occur where and when they do. Specifically, the region of thundersnow across the central USA is attributed to the interaction between of thundersnow occurrence is far enough north to receive the below-freezing temperatures during the winter that are needed for snow. Any further south and snow rarely happens. Second, the region of thundersnow occurrence is far enough south to receive sufficient moisture and instability from the warm waters of the Gulf of Mexico. The lift arises from the ascent associated with low-pressure systems and their attendant fronts moving through this region.

Another region in the USA where thundersnow occurs is over and downwind of the Great Lakes and the Great Salt Lake in Utah (Schultz, 1999). In these cases, cold air blows over relatively warmer open water, producing instability and abundant low-level moisture from evaporation. Circulations resulting from such instability or ascent (orographic lifting) along the coastal terrain may produce lift, resulting in horizontally elongated bands of thundersnow tens of kilometres long.

Another location for thundersnow in the USA is over the Rocky Mountains where air encountering the mountains is forced upward, producing thunderstorms at higher elevations. In thunderstorms, even during the summer, precipitation begins as snow at high altitudes but melts while descending through warmer air below. In the mountains at higher elevations, however, snow does not melt before reaching the mountain surface. Thus, a rain-producing thunderstorm at lower elevations might be a thundersnow storm at higher elevations.

The thundersnow climatology for the USA appears to be quite different from that for the British Isles, western Norway, and northern Europe, although no formal climatology in Europe has been performed. The anonymous reviewer of this paper suggested that thundersnow in these areas of Europe occurs mainly during cold-season snow showers, likely in a post-cold-frontal environment. Thundersnow tends to occur around the north coast of Scotland between November and February, and less commonly in southern Britain between March and early May. Insolation may be so strong in between the showers that the surface air temperatures may be as high as $8^{\circ} \mathrm{C}$. Less commonly, thundersnow can also occur along cold fronts (such as the 28 January 2004 event discussed earlier) and within polar lows.

\section{Impacts and forecasting}

Nearly all lightning injuries and deaths occur during the warm season; however, people may be struck by lightning in the winter. The colder weather has the advantage of keeping more people inside, making it less likely that they would be struck. A man was struck by lightning during a blizzard in Minneapolis, Minnesota, during March 1996, and another man was struck in Vail,
Colorado, in April of that same year. On the afternoon of 23 February 2002, lightning struck a hill in Caribou, Maine, injuring four teenagers who were sledding. Three boys were treated and released at a local hospital, whereas the fourth was critically injured and required hospitalization.

The rarity of thundersnow events means that collecting observations inside clouds to better understand thundersnow occurrence has not been common. One study (Rust and Trapp, 2002) to measure the electric field in winter storms over Utah did not sample any thundersnow events. The limited weather data collected over the past has not developed into improved forecasts of thundersnow. Furthermore, given their rarity, forecasting thundersnow occurrence is generally not a high priority.

A five-year research programme at the University of Missouri-Columbia has been focusing on thundersnow. The emphasis of the project is to develop a forecasting programme for thundersnow events in the central USA. Part of the research project sends teams of scientists and students into the field to take measurements inside thundersnow-producing clouds using instrumented weather balloons. Surface-based instruments take pictures of snow and ice crystals, thus creating detailed records of the precipitation type. In March 2007, researchers intercepted a thundersnow storm, collecting high-quality data on precipitation type, according to Prof. Patrick Market who leads this effort. Although results have not yet been analysed, the experience that Prof. Market's team of researchers develops during these winter storms will hopefully lead to improved weather forecasts for the occurrence of thundersnow.

\section{Conclusion}

Thundersnow is an unusual cold-season convective storm that tends to be associated with heavy snowfall rates. The four ingredients needed for thundersnow are moisture, lift, an unstable atmospheric temperature profile, and below-freezing air in the cloud and near ground level. By identifying regions where these ingredients are likely to come together, favoured areas for thundersnow across the USA (Intermountain West, central USA and downwind of the Great Lakes and Great Salt Lake) can be explained. The rarity of thundersnow events means that we have less knowledge about how these storms become electrified compared to regular warm-season thunderstorms. Nevertheless, a new research project, better instrumentation to observe the inner workings of clouds, and increased emphasis on understanding these unusual storms will hopefully lead to better understanding, and eventually better forecasts, of thundersnow. 


\section{Acknowledgements}

We appreciate the comments that improved this article by Drs Ted Mansell and David Rust from the NOAA/National Severe Storms Laboratory and Prof. Patrick Market from the University of Missouri-Columbia. The following individuals also provided their expertise and time to improve this article: Wendy L. Grebbien and Jennifer J. Vavrek. We also thank an anonymous reviewer who provided valuable comments about thundersnow in Europe. Partial support for Schultz comes from Vaisala Oyj.

\section{References}

Crowe C, Market P, Pettegrew B, Melick

C, Podzimek J. 2006. An investiga-

tion of thundersnow and deep snow

accumulations. Geophys. Res. Lett. 33:

L24812, doi:10.1029/2006GL028214
Curran JT, Pearson AD. 1971. Proximity soundings for thunderstorms with snow. Preprints, Seventh Conference on Severe Local Storms. American Meteorological Society: Kansas City, MO. pp 118-119.

Fraser AB, Bohren CF. 1992. Is virga rain that evaporates before reaching the ground? Mon. Wea. Rev. 120: 1565-1571.

Herschel AS. 1888. Lightning in snowstorms. Q. J. R. Meteorol. Soc. 14: 222-225.

Johns RH, Doswell CA. 1992. Severe local storms forecasting. Wea. Forecasting 7: 588-612

Market PS, Halcomb CE, Ebert R. 2002. A climatology of thundersnow events over the contiguous United States. Wea. Forecasting 17: 1290-1295.

Market PS, Oravetz AM, Gaede D, Bookbinder E, Lupo AR, Melick C, Smith LL, Thomas R, Redburn R. 2006. Proximity soundings of thundersnow in the central United States. J. Geophys. Res. 111: D19208, doi:10.1029/2006JD00706
Rust WD, Trapp RJ. 2002. Initial balloon soundings of the electric field in winter nimbostratus clouds in the USA. Geophys. Res. Lett. 29: 1959, doi:10.1029/ 2002GL015278

Schultz DM. 1999. Lake-effect snowstorms in northern Utah and western New York with and without lightning. Wea. Forecasting 14: 1023-1031.

Wang P.-K, Chu J.-H. (1982) Unusual lightning events in ancient Chinese literature. Weatherwise 35: 119-122.

Correspondence to: Prof. David M. Schultz, Finnish Meteorological Institute, P.O. Box 503, Erik Palménin Aukio 1, Helsinki, Fl-00101, Finland.

E-mail:David.Schultz@fmi.fi

@Royal Meteorological Society, 2009

DOI: 10.1002/wea.376

\section{Anthropogenic snowfall events in the UK: examples of urban weather modification?}

\section{Curtis R. Wood and R. Giles Harrison}

\section{University of Reading, UK}

Snowfall is not confined to frontal or convective weather systems. This was evident from a striking weather image in the August 2008 issue of Weather, which showed a satellite picture of scattered snow patches over the Low Countries immediately following a period of foggy anticyclonic weather (van den Berg, 2008). The snowfall illustrated was typically downstream of urban and industrial areas, raising the possibility that the events were anthropogenic snowfall events (ASEs), associated with fog and artificially injected particles.

Studying such snowfall from fog is important because of the associated local changes and the potential hazard it produces. Since the snow might not have been forecast, a hazard might arise from inadequate gritting of roads; but - perhaps more worryingly - as snowfall is such an obvious event, it provides an objective basis on which the forecast may be widely perceived to have been 'wrong'. Even a light covering of snow alters the local surface albedo. The resulting microclimatological changes could contribute to further differences between the local weather and predictions from forecasting models. Finally, since snow reports are important for climatological records (e.g. used as a threshold climate change indicator), the snow's origin is important.

During freezing fog, it is reasonably common for airborne supercooled liquid fog droplets to come into contact with sub-zero surfaces and solidify on the surfaces to form rime. Large droplets falling from fog essentially form drizzle, but snowflakes (or snowgrains) falling ${ }^{1}$ is perhaps a more unusual occurrence, at least in southern Britain.

The possibility of ASEs in the UK is investigated further here, based on the phenomenology developed from previously reported events.

\section{Anthropogenic snow phenomena}

Precipitation directly caused or influenced by human activity has been reported for many decades, with early reports of drizzle by Blum (1948) and snowfall by Culkowski (1962). ASEs have typically been attributed to effluents from either industrial plants (Charlton and Park, 1984) or power stations (Kramer et al., 1976; Koenig, 1981); almost all reported ASEs

${ }^{1}$ Because of the similarity in the circumstances concerned, we suggest describing drizzle-like snowfall from fog as swizzle. have been in North America. Near power stations, a $1 \%$ increase in annual precipitation can be expected up to a few thousand feet from power station cooling towers (Huff, 1972). As well as local observations, ASEs can be inferred from satellite images (Koenig, 1981; Van den Berg, 2008).

Observations show ASEs can generate snowfall at hundreds of metres to hundreds of kilometres downstream of a power station. At the greater-length scales, and coinciding with natural snowfall, a seederfeeder mechanism has been suggested to operate, whereby snowfall accumulations at the ground are enhanced by up to a factor of two as the natural snow falls through the cooling tower plume (Campistron, 1987). Nearer to the cooling towers, and when there is no natural precipitation present, effects vary depending on whether the near-surface air is foggy or not.

\section{Non-foggy conditions}

When the ambient air is sub-saturated, for anthropogenic precipitation to occur there is probably the need for the cooling tower plume to reach the ground, typically one to five cooling tower heights downstream (Overcamp and Hoult, 1971). Such plume deviation is related to the aerodynamic wake around the cooling tower, which can act to pull the plume downwards, substantially 